\title{
Rainfall-Runoff Prediction based on Artificial Neural Network: A Case Study Priyadarshini Watershed
}

\author{
S.K. Kothe ${ }^{1}$, B.L. Ayare ${ }^{1 *}$, H.N. Bhange ${ }^{1}$ and S.T. Patil ${ }^{2}$ \\ ${ }^{1}$ Department of Soil \& Water Conservation Engineering, ${ }^{2}$ Department of Irrigation \& \\ Drainage Engineering, CAET, DBSKKV, Dapoli, Maharashtra, India-415712 \\ *Corresponding author:
}

\begin{abstract}
A B S T R A C T
\end{abstract}
Hydrological modelling is a powerful technique of hydrologic system investigation for both the research hydrologists and the practicing water resources engineers involved in the

\section{Keywords}

ANN, Modelling, Runoff Prediction,

Statistical performance, Watershed

Article Info

\section{Accepted:}

12 April 2019

Available Online:

10 May 2019 planning and development of integrated approach for management of water resources. In present study, the observed rainfall and runoff data of 2010, 2011, 2013 and 2014years were used as input data. In ANN, input data was divided in 70 per cent, 15 per cent and 15 per cent for training, testing and validation purpose, respectively. Rainfall-runoff models play an important role in water resource management planning and therefore, 70 numbers of different types of models with various degrees of complexity have been developed for this purpose. The output from ANN was tested with statistical parameters, viz. root mean square error (RMSE), mean absolute error (MAE), coefficient of determination $\left(\mathrm{R}^{2}\right)$ and correlation coefficient $(r)$. The rainfall-runoff relationship is one of the most complex hydrologic phenomena and it is based on tremendous spatial and temporal variability of watershed characteristics, precipitation patterns, etc. Therefore other models were not performing well. The ANN model 1-48-1 architecture was selected as the best. The comparisons between the measured and predicted values of runoff showed that the ANN model could be successfully applied and provide high accuracy and reliability for estimation of runoff from un-gauged watershed with rainfall as input parameter.

\section{Introduction}

It is likely that most watersheds or basins of the world are ungauged or poorly gauged. There is a whole spectrum of cases which can be collectively embraced under the term "ungauged basins". Some basins are genuinely ungauged, whereas others are poorly gauged or were previously gauged, where measurements discontinued due to instrument failure and/or termination of a measurement programme. Also, the term "ungauged basin" refers to a basin where meteorological data or river flow, or both, are not measured. In ungauged watersheds, where there are no data, the hydrologist has to develop and use models and techniques which do not require the availability of long time series of meteorological and hydrological measurements. One option is to develop 
models for gauged watersheds and link the model parameters to physiographic characteristics and apply them to ungauged watersheds, whose physiographic characteristics can be determined. Another option is to establish regionally valid relationships in hydrologically similar gauged watersheds and apply them to ungauged watersheds in the region. The stream flow of a watershed is often measured for a limited period and these stream flow data are inefficient for hydrological model calibration and statistical analysis. In this paper, a technique that couples a hydrological model with artificial neural networks (ANNs) is proposed to improve the stream flow simulation and estimation of peak flows for watersheds with limited stream flow data. In recent years, ANNs have become extremely popular for prediction and forecasting of climatic, hydrologic, and water resource variables (Govindaraju and Rao, 2000; Abrahart et al., 2004). Artificial Neural Networks (ANNs) have been used for modelling complex hydrological process, such as rainfall-runoff and have been shown to be one of the most promising tools in Hydrology (Arslancheleng, 2011). Combination of computational efficiency measures and ability of input parameters which describe the physical behavior of hydro-climatologic variables, improvement of the model predictability is possible in artificial neural network environment (Arslancheleng, 2011). Artificial Neural Network (ANN) models have been used successfully to model complex non-linear input-output relationships in an extremely inter disciplinary field. The natural behaviour of hydrological processes is appropriate for the application of ANN method. In recent years, ANNs have been used intensively for prediction and forecasting in a number of water-related areas, including water resource study (El-Shafie et al., 2007), prediction of evaporation (Sudheer et al., 2002), hydrograph simulator, rainfall forecasting. Rainfall runoff relationship is an essential component in the process of water resources evaluation. The relationship of rainfall-runoff is known to be highly nonlinear and complex. Controlling the runoff would require a complete assessment of soil erosion and associated non-point source pollution impacts in the watershed from a long-term perspective. Hence it is needed to study the ANN structure to simulate runoff from rainfall data for particular soil conservation measure and different cropping pattern in ungauged watershed. Keeping this in view study was carried out with the objective that to develop of Rainfall- Runoff model using Artificial Neural Network.

\section{Materials and Methods}

\section{Artificial neural network (ANN) model}

Artificial neural network (ANN) is a massively parallel distributed information processing system that has certain performance characteristics resembling biological neural network of the human brain. An ANN normally consists of three layers, an input layer, a hidden layer and an output layer. Input layer usually receives the input signal values. Neurons in output layer produce the output signal. ANN is essentially useful for modeling and prediction of uncertain and complex phenomena. A neural network can be trained from the previous data to forecast future events, without accurately understanding the physical parameters which influences the presents and future events.

\section{Activation function}

The activation function of a neuron in a neural network is only processing function. It is utilized for the limiting the amplitude of the output of a neuron. Also known as transfer function is referred to as squashing function 
as quashes (limits) the permissible amplitude range to some finite value. It gives output in a range of 0 to 1 .

The mathematical expression of the logistic function is given by

$f(n)=\frac{1}{1+e^{-n}}$

An attempt to improve the accuracy is to use data on discharge excess and sum of rainfall during the last 24 hours from the prediction time is additional input to the network model.

\section{The back propagation algorithm}

The back propagation algorithm uses supervised learning, which means that provide the algorithm with examples of the inputs and outputs we want the network to compute, and then the error (difference between actual and expected results) was calculated. The idea of the back propagation algorithm was to reduce this error, until the ANN learns the training data.

The expression can be written in the mathematical form as follows:

$\mathrm{Q}(\mathrm{t})=f\left(\mathrm{SR}, \mathrm{DQ}, \mathrm{R}\left(\mathrm{t}_{1}-3\right), \mathrm{R}\left(\mathrm{t}_{1}-2\right), \mathrm{R}\left(\mathrm{t}_{1}-2\right), \mathrm{R}(\mathrm{t}-\right.$ 3ts), Q(t-ts), Dq)

Where,

$\mathrm{T}=$ time of prediction, $\mathrm{h} ; \mathrm{t}_{1}=$ time period, (3hrs)

$\mathrm{t}_{1}=$ time to incorporate rainfall (in this case, $\left.\mathrm{t}_{1}=\mathrm{t}-4\right)$

$\mathrm{R}=$ rainfall intensity, $\left(\mathrm{mh}^{1}\right) ; \mathrm{Q}=$ discharge, (cumec)

$\mathrm{SR}=$ summation of rainfall value from $\mathrm{t}-8 \mathrm{t}$ to $\mathrm{t}-3 \mathrm{ts},(\mathrm{mm} / \mathrm{hr})$

$\mathrm{DQ}=$ discharge excess between $\mathrm{Q}$ (t-8ts) and $\mathrm{Q}$ ( $\mathrm{t}-3 \mathrm{ts})$, (cumec).

$\mathrm{Dq}=$ discharge excess between $\mathrm{Q}(\mathrm{t}-3 \mathrm{ts})$ and $\mathrm{Q}$ (t-ts), (cumec).

\section{Procedure for ANN model simulation}

In the ANN model epochs were set up to 1000 iterations. Model training was carried out by using Levenberge-Marquadt algorithm and performance was checked by using mean square error (MSE). Data was divided on random basis. When input as rainfall was given and output as observed runoff in neural network toolbox in MATLAB 7.9 training of the network automatically stops whenever recommended output reached with least errors. After the training of ANN, it gives output in the form of performance plot, training state plot, fit plot and regression plot. The output from ANN was statically tested with the observed runoff by using various statistical parameters viz. RMSE, MARE, coefficient of determination $\left(\mathrm{R}^{2}\right)$ and correlation ( $\mathrm{r}$ ). By comparing these statistical parameters best ANN architecture was selected.

\section{Rainfall-Runoff simulation}

Priyadarshini watershed of CAET was used for development of ANN model for rainfallrunoff. Daily rainfall data of 2010, 2011, 2013 and 2014 year and corresponding runoff data were used for this study.

\section{Results and Discussion}

\section{Runoff estimation by using ANN model}

In the present study, artificial neural network was tested by using logistic sigmoid function and trained with a Levenberg-Marquardt back-propagation algorithm to estimate runoff by artificial neural network. For this purpose the neural network toolbox in MATLAB 7.9 was used. Four years i.e. 2010, 2011, 2013 and 2014 observed rainfall data and observed runoff data sets were used as input data for operation and it consist of total 198 events (Fig. 1). 
Table.1 The Statistical performance of various ANN architectures

\begin{tabular}{|c|c|c|c|c|c|c|c|c|c|c|c|c|c|c|c|c|c|}
\hline $\begin{array}{l}\text { Sr. } \\
\text { No. }\end{array}$ & $\begin{array}{c}\text { ANN } \\
\text { architecture }\end{array}$ & RMSE & MAE & $\mathbf{R}^{2}$ & $\mathbf{r}$ & $\begin{array}{l}\text { Sr. } \\
\text { No. }\end{array}$ & $\begin{array}{c}\text { ANN } \\
\text { architecture }\end{array}$ & RMSE & MAE & $\mathbf{R}^{2}$ & $\mathbf{r}$ & $\begin{array}{l}\text { Sr. } \\
\text { No. }\end{array}$ & $\begin{array}{c}\text { ANN } \\
\text { architecture }\end{array}$ & $\begin{array}{c}\text { RMS } \\
\text { E }\end{array}$ & MAE & $\mathbf{R}^{2}$ & $\mathbf{r}$ \\
\hline 1. & $1-1-1$ & 26.94 & 1604.74 & 0.3495 & 0.6926 & 26. & $1-26-1$ & 17.91 & 999.97 & 0.7124 & 0.8448 & 51. & $1-51-1$ & 17.60 & 948.78 & 0.7224 & 0.8565 \\
\hline 2. & $1-2-1$ & 16.54 & 923.17 & 0.7546 & 0.8693 & 27. & $1-27-1$ & 15.19 & 455.49 & 0.7930 & 0.8973 & 52. & $1-52-1$ & 37.90 & 313.87 & 0.2873 & 0.6387 \\
\hline 3. & $1-3-1$ & 18.67 & 529.79 & 0.7071 & 0.8440 & 28. & $1-28-1$ & 53.85 & 3224.27 & -1.5989 & 0.4937 & 53. & $1-53-1$ & 20.57 & 1096.96 & 0.6205 & 0.8401 \\
\hline 4. & $1-4-1$ & 16.47 & 919.44 & 0.7567 & 0.8700 & 29. & $1-29-1$ & 29.33 & 1148.58 & 0.2290 & 0.7657 & 54. & $1-54-1$ & 23.40 & 1116.13 & 0.5091 & 0.7285 \\
\hline 5. & $1-5-1$ & 46.87 & 2567.35 & -0.9089 & 0.7038 & 30. & $1-30-1$ & 22.59 & 718.50 & 0.5424 & 0.8369 & 55. & $1-55-1$ & 26.73 & 778.92 & 0.3597 & 0.7874 \\
\hline 6. & $1-6-1$ & 17.37 & 1052.46 & 0.7295 & 0.8552 & 31. & $1-31-1$ & 17.99 & 1032.16 & 0.7099 & 0.8545 & 56. & $1-56-1$ & 16.16 & 786.27 & 0.7658 & 0.8767 \\
\hline 7. & $1-7-1$ & 16.52 & 993.512 & 0.7554 & 0.8692 & 32. & $1-32-1$ & 14.55 & 1026.65 & 0.8100 & 0.9002 & 57. & $1-57-1$ & 19.83 & 708.07 & 0.6474 & 0.8277 \\
\hline 8. & $1-8-1$ & 20.00 & 812.24 & 0.6415 & 0.8146 & 33. & $1-33-1$ & 23.87 & 1182.66 & 0.4892 & 0.7442 & 58. & $1-58-1$ & 20.28 & 543.23 & 0.6314 & 0.8060 \\
\hline 9. & $1-9-1$ & 34.28 & 833.16 & -0.053 & 0.6424 & 34. & $1-34-1$ & 14.13 & 862.28 & 0.8209 & 0.9066 & 59. & $1-59-1$ & 21.57 & 736.40 & 0.5829 & 0.7733 \\
\hline 10. & $1-10-1$ & 34.84 & 904.57 & -0.0876 & 0.6307 & 35. & $1-35-1$ & 13.61 & 1032.70 & 0.8338 & 0.9136 & 60. & $1-60-1$ & 16.93 & 931.16 & 0.7428 & 0.8623 \\
\hline 11. & $1-11-1$ & 16.75 & 842.25 & 0.7484 & 0.8654 & 36. & $1-36-1$ & 29.96 & 1095.43 & 0.1952 & 0.7453 & 61. & $1-61-1$ & 31.03 & 1059.23 & 0.1370 & 0.6994 \\
\hline 12. & $1-12-1$ & 62.23 & 6762.68 & -2.4707 & 0.7985 & 37. & $1-37-1$ & 43.88 & 771.81 & 0.7256 & 0.5625 & 62. & $1-62-1$ & 28.99 & 854.96 & 0.2468 & 0.7308 \\
\hline 13. & $1-13-1$ & 29.83 & 743.80 & 0.2025 & 0.7576 & 38. & $1-38-1$ & 17.94 & 1358.47 & 0.7115 & 0.8637 & 63. & $1-63-1$ & 72.24 & 836.94 & -3.6763 & 0.3991 \\
\hline 14. & $1-14-1$ & 17.76 & 810.76 & 0.7173 & 0.8523 & 39. & $1-39-1$ & 17.55 & 1193.56 & 0.7239 & 0.8631 & 64. & $1-64-1$ & 25.51 & 498.95 & 0.4168 & 0.7364 \\
\hline 15. & $1-15-1$ & 49.47 & 100.75 & -1.1927 & 0.5740 & 40. & $1-40-1$ & 14.03 & 590.22 & 0.8236 & 0.9078 & 65. & $1-65-1$ & 14.28 & 1103.38 & 0.8172 & 0.9057 \\
\hline 16 & 1-16-1 & 15.55 & 863.65 & 0.7832 & 0.8864 & 41. & $1-41-1$ & 14.65 & 799.40 & 0.8076 & 0.9002 & 66. & $1-66-1$ & 19.55 & 839.17 & 0.6572 & 0.8253 \\
\hline 17. & $1-17-1$ & 15.96 & 794.54 & 0.7717 & 0.8806 & 42. & $1-42-1$ & 20.02 & 624.04 & 0.6408 & 0.8169 & 67. & $1-67-1$ & 19.34 & 892.22 & 0.6645 & 0.8491 \\
\hline 18. & $1-18-1$ & 14.08 & 967.39 & 0.8223 & 0.9074 & 43. & $1-43-1$ & 20.12 & 1007.51 & 0.6338 & 0.7978 & 68. & $1-68-1$ & 21.24 & 868.55 & 0.5954 & 0.8158 \\
\hline 19. & $1-19-1$ & 302.5 & 963.35 & -81.014 & 0.2704 & 44. & $1-44-1$ & 16.40 & 903.66 & 0.7590 & 0.8729 & 69. & $1-69-1$ & 36.04 & 1025.63 & 0.1638 & 0.6425 \\
\hline 20. & $1-20-1$ & 16.16 & 931.97 & 0.7659 & 0.8763 & 45. & $1-45-1$ & 14.41 & 761.47 & 0.8138 & 0.9021 & 70. & $1-70-1$ & 31.80 & 1025.33 & 0.093 & 0.6870 \\
\hline 21. & $1-21-1$ & 18.25 & 946.21 & 0.7015 & 0.8528 & 46. & $1-46-1$ & 117.1 & 700.30 & -11.300 & 0.3124 & & & & & & \\
\hline 22. & $1-22-1$ & 14.48 & 924.73 & 0.8120 & 0.9023 & 47. & $1-47-1$ & 91.81 & 998.66 & -6.6533 & -0.0865 & & & & & & \\
\hline 23. & $1-23-1$ & 15.60 & 1033.53 & 0.7818 & 0.8843 & 48. & $1-48-1$ & 13.45 & 472.06 & 0.8376 & 0.9188 & & & & & & \\
\hline 24. & $1-24-1$ & 27.72 & 1039.06 & 0.3111 & 0.7348 & 49. & $1-49-1$ & 18.60 & 883.96 & 0.6898 & 0.8481 & & & & & & \\
\hline 25. & $1-25-1$ & 16.30 & 1048.31 & 0.7617 & 0.8732 & 50. & $1-50-1$ & 34.08 & 530.92 & -0.0406 & 0.6960 & & & & & & \\
\hline
\end{tabular}


Fig.1 Comparison of predicted and observed runoff for ANN model 1-48-1

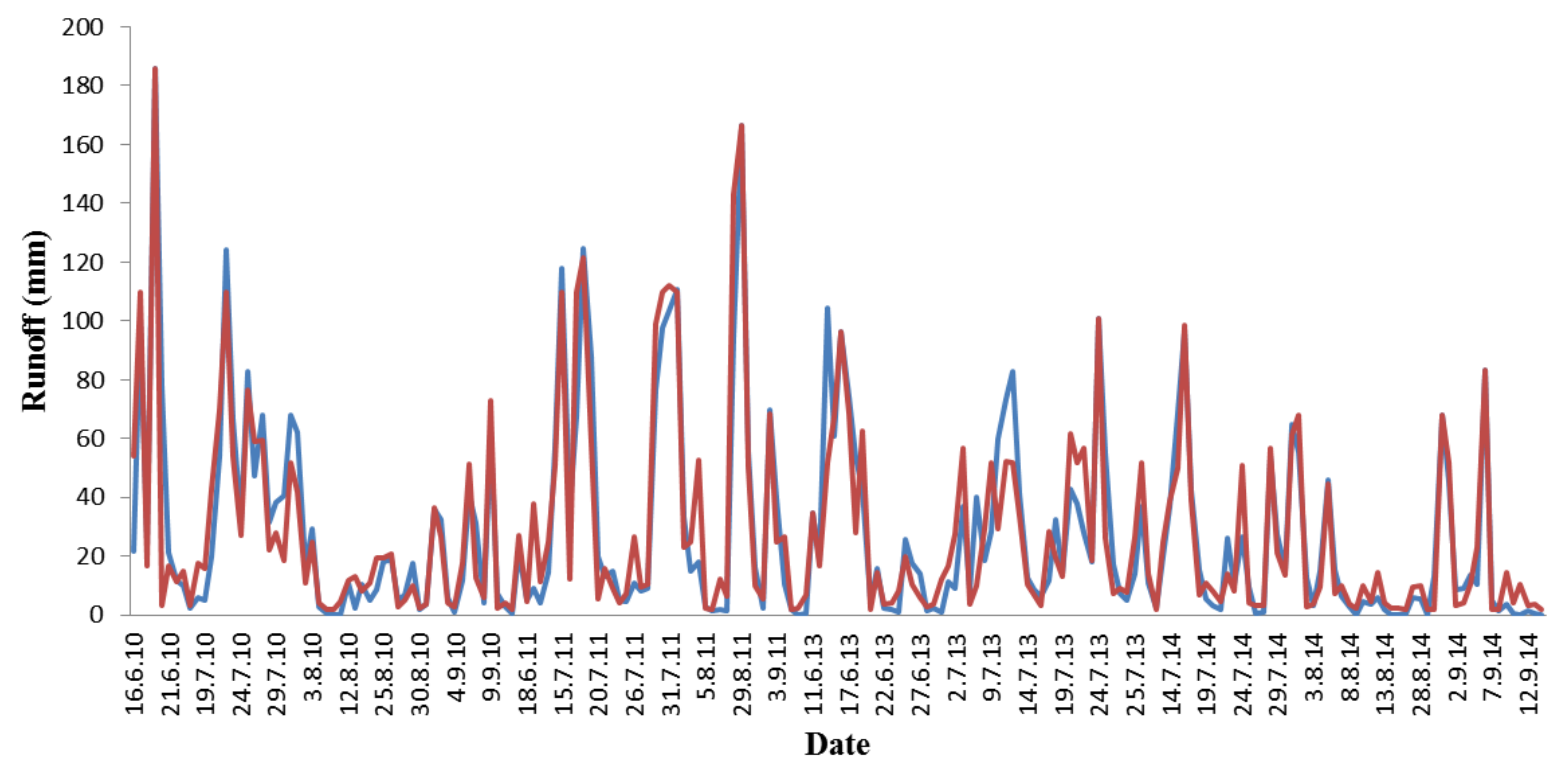

Fig.2 Scatter plot of predicted Vs observed runoff for ANN model 1-48-1

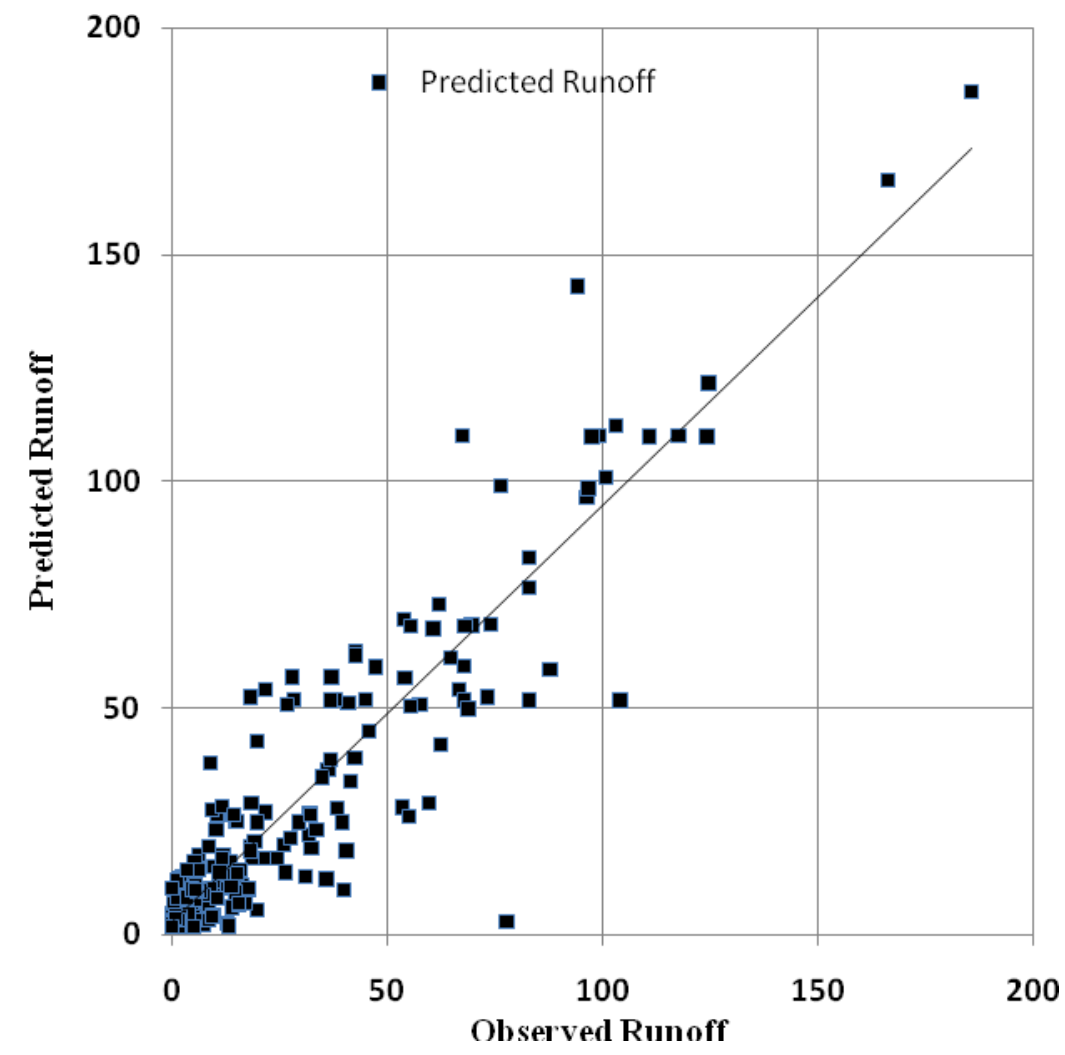

These 198 samples were distributed as 138 for validation and 30 samples (15\%) for samples $(70 \%)$ for training, 30 samples $(15 \%) \quad$ testing purpose in ANN model. 


\section{Statistical analysis by ANN method}

In this case neural network up to 70 hidden neurons in hidden layer were studied, as after 70 hidden neurons it gives very high mean square error. This resulted $1-48-1$ as best model configuration and indicated that 1 neuron in hidden layer fitted best on test data and shows a high degree of accuracy with training data set. ANN with above configuration was trained several iterations and best result were obtained with 13 iterations on the basis of minimum percent mean square error (PMSE) (Fig. 2).

\section{ANN with one input}

Initially neural network was trained by using single input (rainfall) and single output (runoff) and data was divided into 70 percent for training, 15 per cent for validation and 15 percent for testing respectively. From the table 1 the 1-48-1 ANN architecture gives 13.4597, 472.06, 0.8376 and 0.9188 values for RMSE, MAE, Coefficient of Determination $\left(\mathrm{R}^{2}\right)$ and Correlation (r), respectively. The results obtained from Table 1 and ANN of architecture 1-48-1 found suitable for estimation of runoff. As shown in graph the number of scatter points above the average line were more in number hence the result shows that runoff has been slightly over estimated.

In conclusion, the artificial neural network ANN models shows an appropriate capability to model hydrological process. It was useful and powerful tools to handle complex problems compared with other traditional models. In this study, the influences of back propagation efficiencies and enabling of input dimensions on rainfall-runoff modelling capability of the artificial neural network was applied by trying different input dimension. The 1-48-1 ANN architecture gave 13.4597, 472.06, 0.8376 and 0.9188 values for RMSE,
MAE and Coefficient of Determination $\left(\mathrm{R}^{2}\right)$ and Correlation ( $\mathrm{r}$ ), respectively. The performance of ANN 1-48-1 architecture in estimation of runoff from rainfall data was checked statistically. Hence, this ANN 1-48-1 architectures can be adopted to estimate runoff from ungauged watershed with rainfall as input. The comparisons between the measured and predicted values showed that the ANN model could be successfully applied and provide high accuracy and reliability for estimation of runoff from un-gauged watershed with rainfall as input parameter.

\section{References}

Abrahart, R. J., Kneale, P. E., and See, L. M. (Eds.): Neural Networks for Hydrological Modelling, A.A. Balkema Publishers, Rotterdam, The Netherlands, 2004.

Archana S. and Rakesh K. (2012) Artificial Neural Networks for Event Based Rainfall-Runoff Modeling. Journal of Water Resource and Protection, 4: 891897.

Arslan C. A. (2011) Rainfall-Runoff Modelling based on Artificial Neural Network. European journal of scientific research, 65: 490-506.

Avinash A., Mishra S. K., Ram S., Singh J. K. (2006) Simulation of Runoff and Sediment Yield using Artificial Neural Networks. Biosystems Engineering, 94 (4): 597 -613.

Chen, J. and Adams B. (2006) Semi distributed Form of the Tank Model Coupled with Artificial Neural Networks. Journal of Hydrologic Engineering, 11(5): 408-417.

Dawson C. W. and Wilby R. L. (1998) An Artificial Neural Network Approach to Rainfall-Runoff Modelling. Journal of Hydrologycal Sciences, 43: 47-66.

El-shafie A., Mukhlisin M., Najah A. A. and Taha M. R. (2011) Performance of 
Artificial Neural Network and Regression Techniques for RainfallRunoff Prediction. International Journal of the Physical Sciences, 6(8): 1997-2003.

Govindaraju, R. S. and Rao, A. R. 2000 Artificial Neural Networks in Hydrology. Kluwer, Dordrecht

Joshi J., and Patel, V.M. (2011) RainfallRunoff Modeling Using Artificial Neural Network, National Conference on Recent Trends in Engineering \& Technology.

Junsawang P., Asavanant J., Lursinsap C. (2005). Artificial Neural Network Model for Rainfall-Runoff Relationship. Advanced Virtual and Intelligent Computing Center (AVIC). Department of Mathematics, Faculty of Science, Chulalongkorn University, Bangkok, 10330, Thailand.

Kaltech M.A. (2008). "Rainfall-Runoff Modeling Using Artificial Neural Networks (Ann's): modelling and understanding". Caspian Journal of Environmental Science, 6(1): 53-58.

Maier H. R. and G. C. Dandy. (2000) Neural Networks for Prediction and Forecasting of Water Resources Variables: A review of Modeling Issues and Applications Environmental Modeling and Software, 15:101-123.

Minns A.W. and M.J. Hall. (1996) Artificial neural networks as rainfall-runoff models. Hydrological Sciences, 41:399417.

Rajurkar M. P. (2004). Modeling of the Daily Rainfall-Runoff Relationship with Artificial Neural Network. Journal of Hydrology, 285: 96-113.

Riad S. and Mania J. (2004) Rainfall-Runoff Model Using an Artificial Neural Network Approach. Mathematical and Computer Modelling, 4: 839-846.

Singh, P. V., Kumar Akhilesh, Rawat J. S., and Kumar Devendra (2013) Artificial Neural Networks Based Daily RainfallRunoff Model for an Agricultural Hilly Watershed. International Journal of Engineering and Management Science, 4(2): 108-112.

Sudheer K. P. and Jain A. (2002) The internal behavior of Artificial Neural Network river flow models. Hydrol. Process 8:833-844.

Yazdani M. R., Saghafian B., Mahdian M. H., and Soltani S. (2009) Monthly Runoff Estimation using Artificial Neural Network. Journal of Agriculture Science Technology, 11: 355-362.

\section{How to cite this article:}

Kothe, S.K., B.L. Ayare, H.N. Bhange and Patil, S.T. 2019. Rainfall-Runoff Prediction based on Artificial Neural Network: A Case Study Priyadarshini Watershed. Int.J.Curr.Microbiol.App.Sci. 8(05): 1328-1334. doi: https://doi.org/10.20546/ijcmas.2019.805.151 